\title{
Breaking compulsive buying-financial trouble chain of young Malaysian consumers
}

\begin{abstract}
Purpose

The purpose of this study is to examine compulsive buying and its interrelationships with careful spending, loan dependence and financial trouble. This study also aims to investigate the moderating role of gender.

Design/methodology/approach
\end{abstract}

A questionnaire-based survey was conducted. Two hundred and seven responses were collected using purposive sampling technique. Partial least square-structural equation modelling was performed to analyze the proposed hypotheses.

Findings

The salient findings are (1) careful spending negatively influences compulsive buying, (2) compulsive buying positively influences loan dependence and financial trouble, (3) loan dependence positively influences financial trouble, (4) the relationships between careful spending and compulsive buying, and between loan dependence and financial trouble differ between male and female consumers, (5) there is a sequential mediation effect between careful spending and financial trouble and (6) there are gender differences between careful spending and compulsive buying and between loan dependence and financial trouble.

Research limitations/implications

This study empirically validates the role of short-term money attitude, conceptualized as careful spending in compulsive buying context and how it attenuates the consequences of compulsive buying.

Originality/value

This study explains the serial mechanism in which careful spending can be used to counteract financial trouble of youngsters, and further looks into the differences of relationships in term of gender through multi-group analysis.

Keyword: Compulsive buying; Gender; PLS-SEM; Money attitude; Carefull spending; Financial trouble 